\title{
Business English Translation Study under Perspective of Functional Equivalence
}

\author{
Shaowei Li \\ Zaozhuang University, Zaozhuang Shandong, 277160, China
}

Key words: Functional equivalence theory, Business English translation, The source language.

\begin{abstract}
The business English translation demands high accuracy and reliability. However, as a global language, the syntax content of English is relatively complex, one meaning can be expressed by multiple words. Besides it has obvious difference with both the mode of thinking and expression form of the use of Chinese in China. It is also one of the difficulties encountered engaged in English translation work. No matter from the aspects of words, sentences or language expression, Business English has strong professional characteristics while more strict requirement of accuracy. In order to ensure the accuracy and reliability of business English translation, this paper uses the theory of functional equivalence for business English translation study, and on the basis of the theory, the article puts forward some suggestions on the problem of improving the level of business English translation.
\end{abstract}

\section{Introduction}

With the integration of the world economy gradually formed, our country's growing business with the rest of the world, the quality of business English translation has played a decisive significance to the international trade development. The functional equivalence theory put forward by the famous American linguist--Eugene . A . Nida is of great significance in translation of language. Carrying out study on business English translation work by using the theory will inevitably promote the development of business English translation work in the future in our country.

\section{The development and realistic meaning of functional equivalence theory}

Functional equivalence theory is one of the classical theories proposed to eliminate the language cultural differences and accurately reproduce the source language culture so as to make different languages have a unified transfer standard conversion in the process of mutual translation, to avoid content distortion caused by differences of translation standards in the process of translation. Content distortion can not only make the credibility and accuracy of the translation greatly reduced, but also make reader find it hard to understand the true meaning the original article wants to express. The emergence of functional equivalence theory has solved these problems to the great extent.

Due to the regulations of functional equivalence theory, language translation is to use reasonable, fair and natural language to complete the translation of language meaning into a literary form, and then again into source language. And translation work also should satisfy the equity not only with all words and statements, but also with the original text in terms of language style and literary form. Translation work is something not just translating the surface meaning of words or sentences in the original text, but also attaching importance to the deep meaning contained in the word or statement and explaining which accurately combined with the whole meaning of the article. It seems that, in the process of being engaged in translation work, according to the requirements of the relevant theory of functional equivalence, one should meet the dynamic equivalences from four aspects including word equivalence, sentence equivalence, article equivalence and stylistic equivalence etc. Functional 
equivalence theory considers that, in translation, the meaning expressed in translation is more important than that of the form. The expression of form may distort the cultural significance reflected in the original text to make it not be able to have successful cultural communication, leaving an adverse impact on the overall effect of the translation.

\section{The basic characteristics shown by business English translation under the functional equivalence theory}

\section{More frequent use of professional language}

The biggest difference between business English with classroom English lies in the fact that business English is mainly used in business communication and exchange, involving more professional words, unfamiliar words, it would be difficult to grasp and skillfully use which if no enough time were taken on learning and memorizing. However, the classroom English is used in daily communication and learning, mainly involving the words commonly used in everyday life, giving priority to basic words and grammar, it is relatively easy to learn which. Therefore, in order to improve the effect of business English learning, in addition to relying on memorizing and accumulating for a long time, correct learning methods should also be adopted. Giving preference to learning and memorizing fixed vocabulary often used in daily business English, learning some uncommon words one by one and making relevant notes to make it easy to review so as to effectively improve one's business English translation level.

\section{The simplicity and accuracy}

In the process of translation of literature works, in order to embody the emotion expressed by the article and manifest the aesthetic feeling of the text, usually the translated words are modified or rearranged by using the Chinese grammar to make the contents of article not too jerky. However the business English translation pay less attention to the beauty of the text but much attention to the simplicity and accuracy of translation instead. It only has to correctly expressthe meaning of the original article with the shortest statements, the emotion expressed in the article is not important. The vocabulary involved in business English translation is usually specific. Rarely ambiguous words appear. In the process of learning business English, therefore, one should make full use of this feature and learn these specific vocabulary well to improve the efficiency of business English learning. The simplicity and the accuracy of business English translation are not only the characteristics of business English translation work, but also important criteria for the evaluation of the personal ability level of business English translation workers.

\section{Business English translation should keep the logic and thinking of English}

Part translation personnel engaged in business English translation process tend to ignore the importance of English logical thinking on translation work, believe that as long as the literal translation is in accordance with the meaning of the contents of the article, it would be a complete article. In fact it is not the case. Business English translation should fully take the emotion involved in the content into consideration instead of translating the content of the article in accordance with our own thinking and understanding, along the way, it is easy to cause the translation not accord with the actual content, while the translation result lack of accuracy. In addition, because differences exist between the Chinese people and foreigners in the way of thinking and oral expression. So in the process of translation, if the translation staff can't translate from the view of the thinking and oral expression of foreigners, the translation is likely to have a result of too much in Chinese form, making people find it difficult to understand the true meaning the paper wants to express. "eat one 's words" in English, for example, according to our Chinese thought pattern, the word should be translated to eat this word, that is, the meaning of Shiyan, Shiyan in our language means going back on one's word, or one does not complete what he promised. But the correct interpretation of the sentence in English is one should take back what one said before and apologize for this; the correct meaning of "female 
professionals" should be professional woman, however, translation according to our Chinese spoken language expression habit, the meaning of this sentence should be a women-only profession, so different from the actually meaning. Therefore, when engaged in the process of business English translation work, the translation staff have to forget the usual way of thinking and oral expression and use the thinking mode of foreigners to translate business English article to ensure the accuracy and reliability of the translation result.

\section{Suggestions on realizing business English translation under perspective of functional equivalence}

\section{Strengthening the accuracy of the use of vocabulary}

English is different from Chinese we use in China, English words are mainly formed by the arrangement of 26 English letters, permutation and combination by words which can express different meanings, thus forming an article. It seems that the word study is the basis of business English translation. As business English translation has strict requirements for the accuracy of the article content, the grasping of English vocabulary, especially grasping of the specific vocabulary involved in business English translation, determines the work ability of business English translation workers. In the process of engaged in business English translation work, in addition to adequate vocabulary and special meeting outside of business English, the use of words should also be noticed. Among Chinese characters, there are often situations such as one word with more than one meaning, one word with more than one sound etc. The meanings of the same word can express different meanings when used in different statements or contexts. While English is not so complicated, especially the specific vocabulary in business English, is comparatively simple on expressing meanings. In the process of learning business English, therefore, one should attach great importance to the meaning of each word as well as accuracy on vocabulary use and thus improve the accuracy of the translation.

\section{Paying attention to the integrity of the sentence structure}

In an article, the integrity of the sentence structure will significantly affect the fluency of article reading. The article is made up of sentences constituted by countless words. Therefore, an in-depth understanding of the sentence structure of the article can effectively improve the integrity and accuracy of business English translation to ensure the translation smooth and fluent. In the actual work, translators can start with recitation of the most basic professional terms to grasp fixed terms involved in business English translation and accurately apply it in business English translation work to make process of translation more smooth, translation results more accurate while the own level of business English translation significantly improved.

\section{Strengthen the grasp of the main structure and ideas of the article}

Under the perspective of functional equivalence, business English translation should pay attention to textual equivalence, contents of article should illuminate the theme as well as highlight the key points to ensure accuracy and rationality of translation content. In the actual business English translation work, many words can be used to express a meaning. E-commerce business, for example, in English can be expressed by both E_Commerce and E_Business. But in the actual translation, whether E_Commerce or E_Business is suitable? This should be judged according to the meaning expressed by the article. E_Commerce indeed has the meaning of e-commerce business, but during the process of use, it mainly refers to the relation between the customer and the merchants of purchased items or the relation between the customer and the service supplier when customers are enjoying their online services. Compared with E_Commerce, the range contained by E_Business is more broad. E_Business contains not only the commercial relations described by E_Commerce, but also the relationship between the producers and providers of raw materials, the relationship between suppliers and government departments etc. It is a kind of business relationship with social nature. If in the 
description of electronic business relations with social nature, using E_Commerce would seem to be not so appropriate. Therefore, in the process of business English translation, one may use less words to express the same meaning so as not to make content not expressed clearly, ensuring that the article language is smooth, easy to read and understand.

In the process of business English translation, avoid by all means is a paragraph or a chapter as the core of translation. One should understand the content the article wants to express from the perspective of the whole article and thus take this as the core to translate the article. Don't focus too much on the role of a sentence or a word in the article. One should first understand the body and ideas of the full text from the perspective of the overall structure, and then deliberate sentence by sentence, word for word so as to effectively guarantee the quality of business English translation. Overall first, then the specific. This is the basic requirement for Business English translation under the perspective of functional equivalence. Only by making sure that the article overall meaning understood can one clear the details in the article. This is very important for business English translation work.

\section{Highlighting the distinctive characteristics of the whole article style}

The so-called style, is a kind of text structure which can separately form an article. It is not only a standard for text composition, but also a kind of special cultural phenomenon. By this token, style belongs to a product in the category of form reflecting the essential feature of article from content to form from an overall perspective. Therefore, in the process of business English translation, the emphasis on style should be improved. Only under the condition that the literary structure of the translation is kept the same with that of the original text, style not changed, can translation reflect its own significance and value. If the overall style and literary structure of the translation is non-equivalence with that of the original text, the user when reading would feel hard to understand the meaning the original text wants to express. From the perspective of the whole style of business English article, Business English has a certain nature of illustration with its text style relatively strong, content most practical and realistic. It illustrates the actual condition of things happened without any personal emotion. Only by doing this, can accurate and reliable business English translation be ensured. If there was too much personal emotion involved in the translation, it would not be scientific analysis and explanation on the objective things, but personal opinion and suggestion on the objective things. This will not only distort the content the original text wants to express, but also make users easy to suspect the authenticity and reliability of the article, eventually the accuracy of the article would be affected. From this perspective, business English translation under the perspective of functional equivalence can highlight the main structure of the article. It embodies the integral style of the article, greatly improves the authenticity and the credibility of the translation and thus promotes the improvement of business English translation.

\section{Conclusion}

From the point of the current situation, as the most advanced theory in translation, functional equivalence theory has played a guiding role in the development of business English translation work of our country. Functional equivalence theory can not only strengthen the translators' understanding of business English, but also can effectively improve their ability of English translation. If in the process of translation, the functional equivalence could not achived, the meaning of the translation would be inconformity with the meaning of the original text. The content of the original text will be distorted to affect the normal conduct of business activities. As a bridge which is linked with the international trade in our country, the quality of translation of business English translation work will directly affect whether our country's international trade and business activities could go smoothly. Therefore, strengthening business English translation study under the perspective of functional equivalence has laid a solid foundation for our country's foreign trade and economic development. 


\section{References}

[1] Zhou Chen, Strategy and means of dynamic equivalence in business translation -- taking the English translation of the publicity materials of the first Beijing SEC as example, Ningbo university, 2014.

[2] Zhao Mingyue, Xiao-hui Zhang, Based on the application of functional equivalence theory in business English translation, Journal of Yalu River monthly. 2016 (01).

[3] Xiu-qin Li, Business English equivalent translation study under the perspective of functional discourse analysis, Journal of market modernization, 2014 (26) : 164-167.

[4] Zhang Xialing, Contrast research on two Chinese translation versions of Walden under Nida's functional equivalence perspective, North University of China, 2016.

[5] Yu Deng, Contrast research on two translation versions of Three Character Primer under the functional equivalence perspective--taking translation of Zai Lisi and translation of Wang Baotong as an example, Southwest Jiaotong university, 2016. 